\title{
INORGANIC PHOSPHATE RESPONSE TO INTRAVENOUS GLU- COSE ADMINISTRATION IN PROGRESSIVE MUSCULAR DYSTROPHY
}

\author{
By D. W. VAN BEKKUM AND A. QUERIDO
}

(From the Department of Diseases of Metabolism and Endocrinology, Medical Clinic, University
Hospital, Leiden, Holland)

(Submitted for publication June 16, 1953; accepted July 1, 1953)

\section{INTRODUCTION}

One outstanding biochemical finding in progressive muscular dystrophy (P.M.D.) is excessive creatinuria. Much of the experimental work on the disease therefore has been centered on creatinecreatinine metabolism. The conclusion has now been reached that the creatinuria in this condition arises from a normal endogenous creatine production in the presence of impaired removal of creatine from the blood stream as a result of the severe diminution of muscle mass (1). It has been furthermore inferred that such parts of the muscles which survive, remove creatine at a normal rate. This decrease in functional muscle mass appears to be a common feature in all distinct cases of progressive muscular dystrophy.

In view of the well established role of carbohydrates as a source of energy in muscular activity, it is surprising that until now hardly any evidence has become available of a disturbance of carbohydrate metabolism in P.M.D. Abnormalities in glucose metabolism have been reported, including hypoglycemia, by McCrudden and Sargent $(2,3)$, reduced sugar tolerance by Janney, Goodhart, and Isaacson (4), and increased utilization of glucose by Magee (5), but more careful studies by Shank, Gilder, and Hoagland failed to confirm these results (6).

In evaluating these negative findings of oral and intravenous glucose tolerance studies, it should be kept in mind that in the process of the removal of glucose from the blood stream in fasting subjects, the capacity of the liver is probably large enough to compensate for any deficiency on the part of the musculature. However, a crude measure of the respective portions removed by these tissues seems to be possible by the simultaneous recording of inorganic serum phosphate during the glucose tolerance test. Pollack and his coworkers (7) have demonstrated that phosphate is removed from a glucose and phosphate-containing perfusion fluid by the isolated hind limb, but not by the isolated liver of the dog. Recently, the estimation of a blood glucose and inorganic phosphate curve, after an oral or intravenous glucose load, has been used for diagnostic purposes in diabetes mellitus, various forms of liver dysfunction and in the study of glucose resorption in tropical sprue (Forsham and Thorn [8], Volk and Lazarus [9], and Fourman [10]).

In the present report, this method has been used in the study of five cases of P.M.D., and the results have been compared to those obtained in normal subjects.

\section{METHODS}

Ten normal subjects (seven males and three females), and five cases of P.M.D. (three males and two females) were studied. In four patients the disease was longstanding and had progressed to various degrees of invalidism. In one case (J. v. O.), muscular weakness was not pronounced and the diagnosis was ultimately founded on the resemblance of electromyographic records with those of her brother (case W. v. O.) who is severely crippled by the disease.

All subjects were instructed to ingest liberal amounts of carbohydrates during a three-day period preceding the test. The experiments were started at $8: 30 \mathrm{a} . \mathrm{m}$. on fasting subjects, the last meal having been taken before 8 p.m. on the previous day. A 20 per cent or $\mathbf{4 0}$ per cent aqueous solution of the glucose was injected in the course of 5 to 10 minutes at a total amount of $1 / 2 \mathrm{Gm}$. per $\mathrm{Kg}$. body weight. During the test the subjects were kept in the recumbent position and were not allowed to smoke.

Immediately before and at intervals of $15,30,60,90$, and 120 minutes after the intravenous administration of glucose, venous blood was withdrawn.

The blood was collected in tubes containing powdered sodium fluoride and this was immediately mixed with the sample. Two-tenths ml. of the whole blood was removed for duplicate glucose estimations, using the method of Hagedorn and Jensen (11). Thereafter, the sample was centrifuged and inorganic phosphate was estimated in the plasma by the method of Briggs (12). The slight degree of hemolysis, which occurred in some samples, apparently 


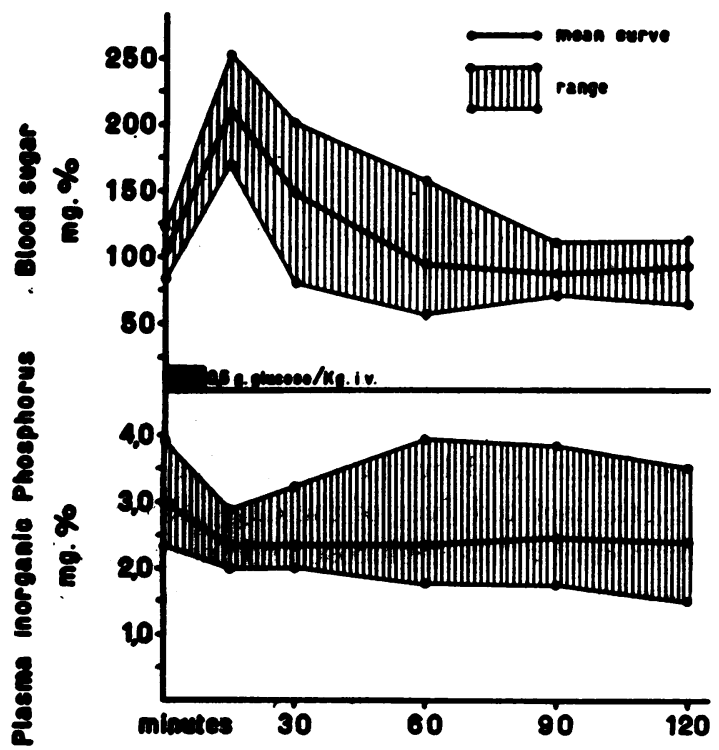

Fig. 1. Changes in Blood Glucose and Plasma Inorganic Phosphorus after a Standard I.V. Glucose Load in Normal Subjects

did not influence the results, presumably because of effective inhibition of breakdown of cellular organic phosphates by the fluoride.

\section{RESULTS}

The data obtained with normal subjects are depicted in Figure 1. The initial value and the lowest value recorded at any time during the test of inorganic plasma phosphate are given for each individual case in Table $I$. The mean of the percentage maximum decrease of the normal individuals (28 per cent) agrees well with that given by Forsham

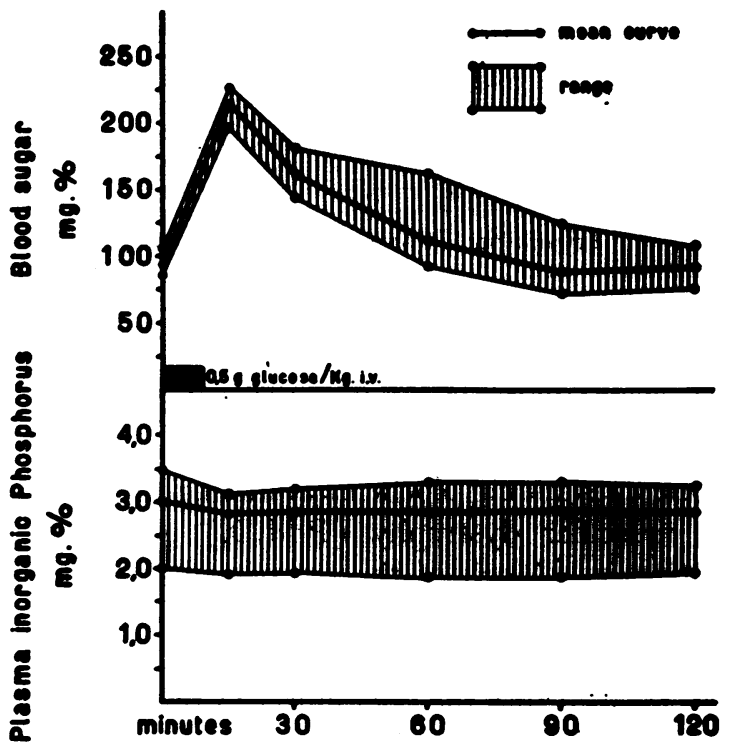

Fig. 2. Changes in Blood Glucose and Plasma Inorganic Phosphorus after a Standard I.V. Glucose Load in Patients with Progressive Muscular DYSTROPHY

and Thorn (8), i.e., 25 per cent for 20 normal subjects. The results of these authors are not wholly comparable to ours because they infused the glucose over a 30 -minute period.

In the cases of P.M.D., the mean glucose tolerance curve (Figure 2 ) is not significantly different from the normal. It should be mentioned that one patient (Case v. D.) showed a definitely delayed glucose response, but in the four others, a perfectly normal glucose curve was obtained.

The fall in plasma inorganic phosphate was poor in all patients and the mean maximum fall was only

TABLE I

Initial values and minimal values of plasma inorganic phosphorus during i.v. glucose tolerance test in normal and diseased subjects

\begin{tabular}{|c|c|c|c|c|c|c|c|}
\hline \multirow[b]{2}{*}{ Subject } & \multicolumn{3}{|c|}{ Normal subjects } & & \multicolumn{3}{|c|}{ Cases of P.M.D. } \\
\hline & $\begin{array}{c}\text { Initial } \\
\text { value } \\
\text { mg. } \%\end{array}$ & $\begin{array}{c}\text { Lowest } \\
\text { value } \\
\text { mg. \% }\end{array}$ & $\begin{array}{c}\text { Maximal } \\
\text { fall in \% } \\
\text { of initial } \\
\text { value }\end{array}$ & Case & $\begin{array}{c}\text { Initial } \\
\text { value } \\
m g . \%\end{array}$ & $\begin{array}{c}\text { Lowest } \\
\text { value } \\
m \boldsymbol{m g .} \%\end{array}$ & $\begin{array}{c}\text { Maximal } \\
\text { fall in \% } \\
\text { of initial } \\
\text { value }\end{array}$ \\
\hline \multirow[t]{2}{*}{$\begin{array}{ll}\text { W } & \sigma^{7} \\
\mathbf{P} & 9 \\
\mathbf{G} & \sigma^{7} \\
\mathbf{J} & \sigma^{7} \\
\mathbf{J} & \mathbf{q} \\
\mathbf{K} & \sigma^{7} \\
\mathbf{Z} & \sigma^{7} \\
\mathbf{B} & \sigma^{7} \\
\mathbf{R} & \sigma^{7} \\
\mathbf{V} & \mathbf{q}\end{array}$} & $\begin{array}{l}3.70 \\
2.96 \\
3.90 \\
2.55 \\
2.36 \\
3.43 \\
2.99 \\
2.58 \\
2.96 \\
2.77\end{array}$ & $\begin{array}{l}2.80 \\
1.97 \\
3.25 \\
1.49 \\
1.99 \\
1.83 \\
2.20 \\
1.82 \\
2.06 \\
2.23\end{array}$ & $\begin{array}{l}24 \\
33 \\
17 \\
42 \\
16 \\
47 \\
26 \\
29 \\
30 \\
20\end{array}$ & $\begin{array}{ll}\text { D } & 0^{x} \\
\text { B } & 9 \\
\text { A } & 0^{x} \\
\text { O } & 0^{x} \\
\text { O } & 9\end{array}$ & $\begin{array}{l}2.08 \\
3.06 \\
3.05 \\
3.43 \\
3.43\end{array}$ & $\begin{array}{r}1.81 \\
2.71 \\
2.82 \\
3.15 \\
3.01 \\
\text { an }(5)\end{array}$ & $\begin{array}{r}13 \\
11 \\
8 \\
8 \\
12 \\
10\end{array}$ \\
\hline & & n (10) & $\overline{28}$ & & & & \\
\hline
\end{tabular}


10 per cent. The difference between this value and the corresponding one for the normal subjects ( 28 per cent) is highly significant $(P<0.001)$ with no overlapping between the two groups.

\section{DISCUSSION}

The decreased phosphate response to glucose injection in the cases of P.M.D. is very probably a reflection of a diminished phosphorylation in the muscle tissue. This in turn could be regarded as the result of the decrease in functional muscle mass. Increased urinary elimination of the injected glucose cannot be responsible for these findings, because of the normal blood glucose curves. When checked in two cases, the glucosuria was found to be less than 2 per cent and 3 per cent of the total dose administered, respectively. Our data do not provide evidence for a correlation between the amount of remaining intact muscle tissue, $e: g$., the severity of the disease and the degree of impairment of the phosphate response. One completely crippled case (v. D.) showed a maximum fall of 13 per cent, while in another very light case (J. v. O.) a maximum fall of 12 per cent was recorded. Furthermore, it is not known to what extent the amount of muscle tissue or of muscle function must decrease in order to be detected as a decreased phosphate response.

On the other hand the possibility remains of a specific biochemical lesion in the diseased muscle, involving a block somewhere in the glycolytic chain of reactions. However, most of the enzymatic and chemical changes reported can be accounted for by relative increase of collagenous material and fat (Nevin [13], Reinhold and Kingsley [14], and Hoagland [15]), and the few indications of primary changes (Hoagland [15], and Dreyfus, Schapira, and Schapira [16]) are in need of confirmation.

The decreased phosphate response reported here should, therefore, be regarded as another manifestation of the diminution of functional muscle mass, although it is realized that similar studies in other forms of muscle disease are still required to support this opinion.

\section{SUM MARY}

Variations in plasma inorganic phosphate levels in response to intravenous administration of glu- cose have been studied in normal subjects and in five cases of progressive muscular dystrophy. The fall in inorganic phosphate was significantly less in the patients.

\section{ACKNOWLEDGMENTS}

Our thanks are due to Prof. Dr. G. G. J. Rademaker, Department of Neurology, University Hospital, Leiden, Netherlands and Dr. Ed. Hoelen, Neurological Department, "Ursula-Kliniek," Wassenaar, Netherlands, for their cooperation in sending in patients and performing the neurological examinations.

\section{REFERENCES}

1. Roche, M., Benedict, J. D., Yü, T. F., Bien, E. J., and Stetten, De. W., Jr., Origin of urinary creatine in progressive muscular dystrophy. Metabolism, 1952, 1, 13.

2. McCrudden, R. H., and Sargent, C. S., Hypoglycemia and progressive muscular dystrophy. Arch. Int. Med., 1916, 17, 465.

3. McCrudden, F. H., and Sargent, C. S., Chemical changes in the blood and urine in progressive muscular dystrophy, progressive muscular atrophy and myasthenia gravis. Arch. Int. Med., 1918, 21, 252.

4. Janney, N. W., Goodhart, S. P., and Isaacson, V. I., The endocrine origin of muscular dystrophy. Arch. Int. Med., 1918, 21, 188.

5. Magee, M. C., Creatine and creatinine metabolism in progressive muscular dystrophy. Am. J. Dis. Child., 1932, 43, 19.

6. Shank, R. E., Gilder, H., and Hoagland, C. L., Studies on diseases of muscle. I. Progressive muscular dystrophy; a clinical review of forty cases. Arch. Neurol. \& Psychiat., 1944, 52, 431.

7. Pollack, H., Millet, R. F., Essex, H. E., Mann, F. C., and Bollman, J. L., Serum phosphate changes induced by injections of glucose into dogs under various conditions. Am. J. Physiol., 1934, 110, 117.

8. Forsham, P. H., and Thorn, G. W., Changes in inorganic serum phosphorus during the intravenous glucose tolerance test as an adjunct to the diagnosis of early diabetes mellitus. Proc. Am. Diabetes A., 1949, 9, 3.

9. Volk, B. W., and Lazarus, S. L., A clinical study of the pathogenesis of the diabetic syndrome: Use of a modified glucose insulin tolerance test combined with the change of serum inorganic phosphorus after glucose administration. Am. J. Digest. Dis., 1951, 18, 269.

10. Fourman, L. P. R., Changes in blood phosphate after ingestion of glucose and fructose in sprue. Brit. $M$. J., 1947, II, 411.

11. Hagedorn, H. C., and Jensen, B. N., Zur Microbestimmung des Blutzuckers mittels Ferricyanid. Biochem. Ztschr., 1923, 135, 46.

12. Briggs, A. P., A modification of the Bell-Doisy phosphate method. J. Biol. Chem., 1922, 53, 13. 
13. Nevin, S., A study of the muscle chemistry in myasthenia gravis, pseudohypertrophic muscular dystrophy and myotonia. Brain, 1934, 57, 239.

14. Reinhold, J. G., and Kingsley, G. R., The chemical composition of voluntary muscle in muscle disease: A comparison of progressive muscular dystrophy with other diseases together with a study of effects of glycine and creatine therapy. J. Clin. Invest., 1938, 17, 377.
15. Hoagland, C. L., Some biochemical problems posed by a disease of muscle. Currents in Biochemical Research, Green, D. E., ed., New York, Interscience Publishers, Inc., 1946, 413.

16. Dreyfus, J. C., Schapira, G., and Schapira F., Etude de la teneur en collagène, aldolase et phosphorylases musculaires au cours des myopathies humaines. Résumés des communications II ${ }^{\bullet}$ Congrès international de Biochemie, Paris, 1952, 422. 